\title{
Lateral Rectus Palsy in A Case of Mediastinal Yolk Sac Tumour
}

\section{Abhishek Onkar ${ }^{1}$, Saurabh Samdariya ${ }^{2}$, and Suwarna Suman ${ }^{1}$}

${ }^{1}$ Department of Ophthalmology, AlIMS Jodhpur, India

${ }^{2}$ Department of Radiation Oncology, AlIMS Jodhpur, India

Corresponding author: Abhishek Onkar, Room No.309, Resident's Hostel, AllMS Jodhpur Residential Complex, Basni Industrial Area, Phase-2, AlIMS Jodhpur, India, Tel: +91-9871984534; E-mail: onkaratdmch@gmail.com

Rec Date: March 10, 2017, Acc Date: April 12, 2017, Pub Date: April 15, 2017

Citation: Onkar A, Samdariya S, Suman S. Lateral Rectus Palsy in A Case of Mediastinal Yolk Sac Tumour. Med Case Rep, 3:2.

\section{Abstract}

Aims: To report a case of mediastinal yolk sac tumor with distant metastasis and isolated, right lateral rectus palsy.

Settings and design: Case report.

Methods and material: A 16-year-old male with history of left sided knee swelling for 3 months and inward turning of right eye for 20 days underwent a thorough ophthalmic examination followed by imaging investigations and serology.

Results: Lateral rectus palsy in this case may be idiopathic or it may be because of CSF metastasis. In the present case, the tumor was originally thought to be osteosarcoma of knee. But the isolated right rectus palsy without any other ophthalmological sign prompted thorough investigations. The imaging investigations thus initiated revealed the primary tumor to be a mediastinal yolk sac tumor with distant metastasis.

Conclusions: Isolated lateral rectus palsy in a known case of tumor should be properly evaluated with appropriate imaging techniques and investigations.

Keywords: Lateral rectus palsy; Yolk sac tumor

\section{Case Report}

The patient, 16 year old male student, resident of Basni village, Jodhpur, Rajasthan presented with complaints of swelling of left knee for 3 months and inward turning of right eye as noted by parents for 20 days. There was no history of trauma, febrile episodes or drug abuse. No family history of diabetes mellitus, hypertension, tuberculosis, arthritis or cancer.

He was completely devoid of any symptoms 3 months back when he developed mild dry cough and painful swelling of left knee. He received local treatment in his village. Cough was relieved but the knee swelling kept enlarging. So, after 2 months he consulted orthopaedic surgeon nearby his village.
Fine Needle Aspiration Cytology of the swelling was performed and it revealed malignant bone forming tumour suggestive of osteosarcoma. In the meanwhile, the patient also developed inward turning of right eye as noted by parents. He was then referred to the Oncology department of AlIMS, Jodhpur (Figures 1 and 2).

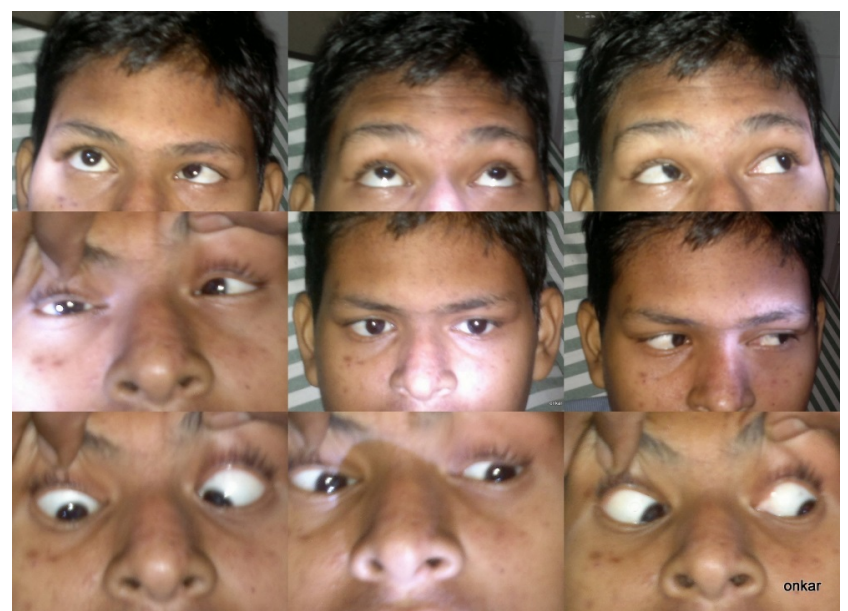

Figure 1 External photograph of primary gaze and 9 cardinal directions of gaze depicting limitation of abduction of right eye in right gaze.

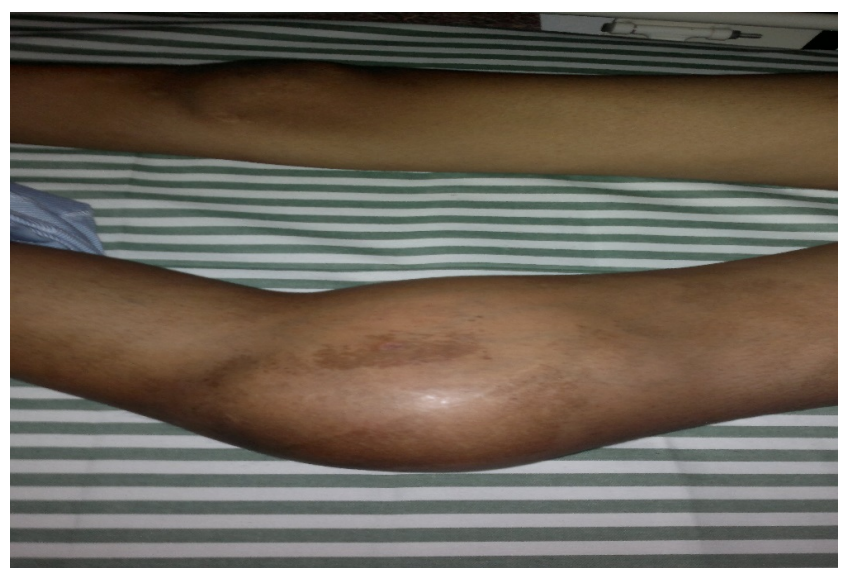

Figure 2 External photograph depicting swelling of left knee. 
General condition was found to be normal with no pallor, icterus, clubbing, cyanosis or lymphadenopathy. Systemic examination revealed diminished breath sounds on left hemithorax and it was dull on percussion. The left knee swelling measured $14 \mathrm{~cm} \times 12 \mathrm{~cm}$ approximately and it was non-tender and firm in consistency.

Biopsy from left knee swelling gave the impression of a round cell tumour. MRI left knee revealed a tumour of dimensions $8.6 \times 5.7 \times 5.1 \mathrm{~cm}$. It was a primary osseous malignancy of left distal femur-medial meta/epiphysis with epiphyseal involvement by tumour (Figure 3).

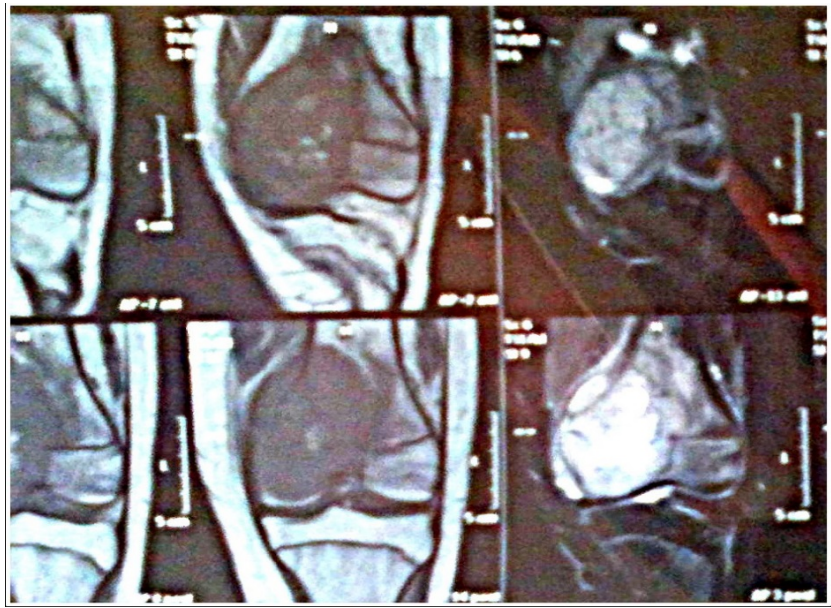

Figure $3 \mathrm{MRI}$ left knee: primary osseous malignancy of left distal femur-medial meta/epiphysis.

Ophthalmological reference for inward turning of right eye (as observed by parents) was sought. There was no complaint of diplopia, headaches or vomiting. There was a slight head tilt towards right. On ophthalmic examination limitation of abduction of right eye was observed. Movement in other gazes were unrestricted and full. The asymmetry between the eyes was more pronounced on right lateral gaze (Figure 1). Forced duction test was found to be negative. Snellen's Visual acuity was 6/6 OU, NVA-N6 OU. Colour vision was normal with Ishihara's plates OU. IOP was found to be $14.6 \mathrm{~mm}$ of $\mathrm{Hg}$ OU with Schiotz tonometer (5.5 gm). Confrontation was found to be normal OU. Convergence was normal, up to nose. Hirschberg's test found the light reflex under the pupillary margin OD. Prism cover test revealed an esotropia of 14 PD. Anterior segment examination revealed no abnormality. Fundus examination was found to be normal with normal sized, round disc, distinct margins, C/D ratio of 0.2 and healthy pink neuro-retinal rim OU. Isolated right lateral rectus palsy was diagnosed. CE-MRI of brain was advised. It revealed mild asymmetric dilatation of right lateral ventricle with contra lateral deviation of septum pellucidum without demonstrable focal lesion or periventricular ooze? Partial obstruction at the level of foramen of Monroe was suggested. This prompted thorough investigations to rule out secondary metastasis (Figure 4).

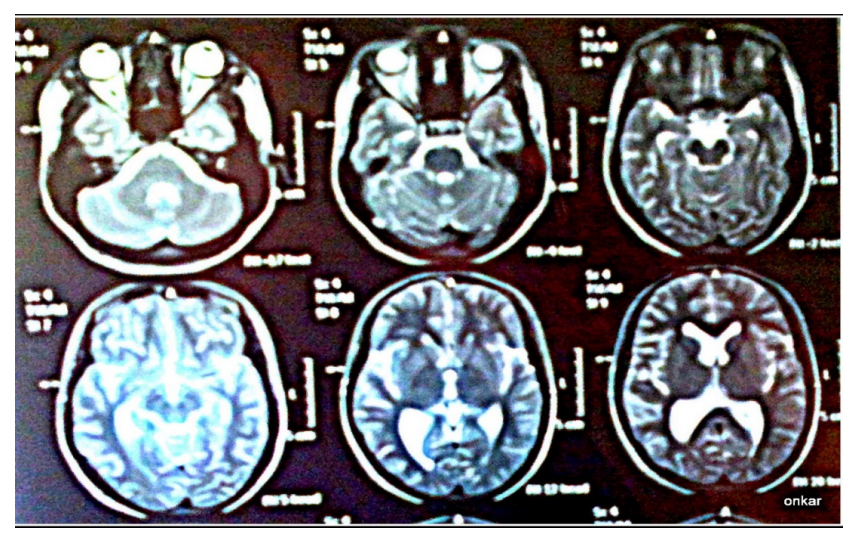

Figure 4 CE-MRI Brain: mild asymmetric dilatation of right lateral ventricle with contralateral deviation of septum pellucidum. Partial obstruction at the level of foramen of monro was suggested.

The battery of investigations that were done thereafter revealed the following:

Plain CT thorax revealed a large well defined heterogenous soft tissue density mass lesion seen in left hemi thorax. Mass was predominantly solid (CT attenuation equal to soft tissue density $30 \mathrm{HU}$ to $35 \mathrm{HU}$ ) but cystic area of fluid density also noted. Mediastinum pushed to right side. Possibility of mediastinal teratoma was raised (Figure 5).

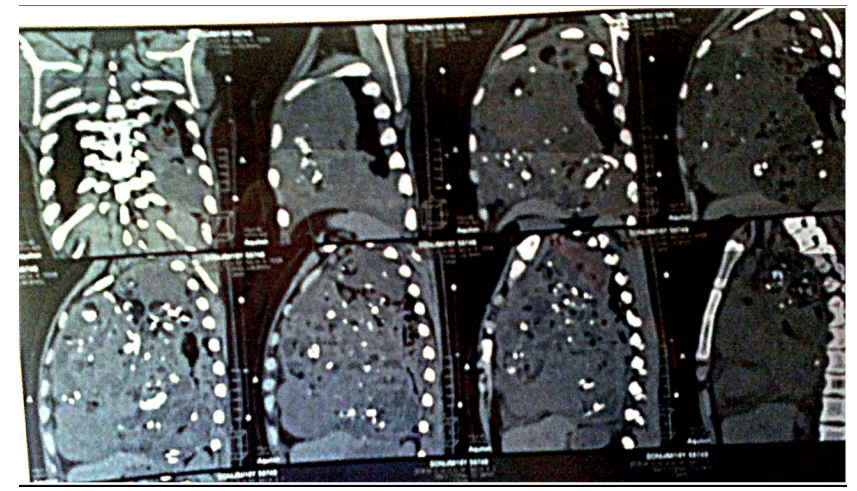

Figure 5 CT Thorax: Mediastinal tumor with involvement of vertebrae.

USG abdomen demonstrated left mild pleural effusion. CECT abdomen and pelvis revealed multiple focal lesions in both lobes of liver suggestive of metastasis. Bony metastasis of lumbar and sacral vertebra with multiple metastasis to right lung. IHC confirmed metastatic deposits of yolk sac tumour (MIC-2+, AFP focally positive, Pan cytokeratin+) (Figure 6). 


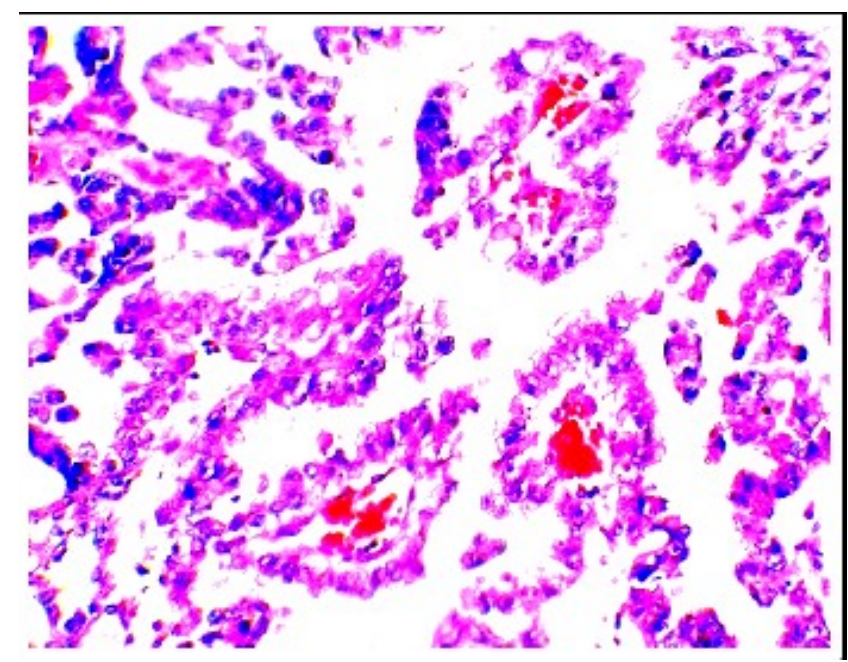

Figure 6 Round cell evident with perivascular Schiller-Duval bodies.

Blood investigations revealed the following- Serum AFP was found to be raised excessively with values of $1,20,371 \mathrm{ng} / \mathrm{ml}$, S. ALP: 137 U/L, S. LDH: 982 U/L, S. $\beta$-HCG: $14.8 \mathrm{mIU} / \mathrm{ml} \mathrm{CBC:}$ $\mathrm{Hb}: 8.8 \mathrm{gm} / \mathrm{dl}$, TLC: 9200 cells/ul, Platelets: $1.99 \mathrm{lac} / \mathrm{ul}$.

Based on the findings of mediastinal tumour with elevated serum alfa-fetoprotein and metastatic lesions also revealing raised local alfa-fetoprotein, diagnosis of mediastinal yolk sac tumour with distant metastases was made. Serum alfa fetoprotein is the primary tumour marker for yolk sac tumor [1]. Poor prognosis was explained to the parents and the patient was put on BEP chemotherapy regimen.

In paediatric patients, acquired Isolated lateral rectus palsy can be due to many causes like trauma, neoplasm, post viral, increased intra-cranial pressure, inflammation or idiopathic. Holmes et al reported $36 \%$ cases of lateral rectus palsy from undetermined causes while Lee et al observed 5\% idiopathic cases [2,3]. Lateral rectus palsy in this case may be idiopathic or it may be because of CSF metastasis. In the present case, the tumour was originally thought to be osteosarcoma of knee. But the isolated right rectus palsy without any other ophthalmological sign prompted thorough investigations. The imaging investigations thus initiated revealed the primary tumour to be a mediastinal yolk sac tumour with distant metastasis. To conclude, every case of isolated lateral rectus palsy should and must be thoroughly investigated by proper imaging techniques.

\section{References}

1. Ballas M (1974) The significance of alpha-fetoprotein in the serum of patients with malignant teratomas and related gonadal neoplasms. Ann Clin Lab Sci 4: 267-275.

2. Holmes JM, Mutyala S, Maus TL, Grill R, Hodge MS, et al. (1999) Pediatric third, fourth and sixth nerve palsies: A population based study. Am J Ophthalmol 127: 388-392.

3. Lee MS, Galetta MD, Volpe NJ, Liu, GT (1999) Sixth nerve palsies in children. Pediatr Neurol 20: 49-52. 